University of Nebraska - Lincoln

DigitalCommons@University of Nebraska - Lincoln

1999

\title{
Satellite-Based Adjustments for the Urban Heat Island Temperature Bias
}

Kevin P. Gallo

National Climatic Data Center, Kevin.P.Gallo@noaa.gov

Timothy W. Owen

National Climatic Data Center

Follow this and additional works at: https://digitalcommons.unl.edu/natrespapers

Part of the Natural Resources and Conservation Commons

Gallo, Kevin P. and Owen, Timothy W., "Satellite-Based Adjustments for the Urban Heat Island Temperature Bias" (1999). Papers in Natural Resources. 190.

https://digitalcommons.unl.edu/natrespapers/190

This Article is brought to you for free and open access by the Natural Resources, School of at DigitalCommons@University of Nebraska - Lincoln. It has been accepted for inclusion in Papers in Natural Resources by an authorized administrator of DigitalCommons@University of Nebraska - Lincoln. 


\title{
Satellite-Based Adjustments for the Urban Heat Island Temperature Bias
}

\author{
KeVin P. Gallo \\ Office of Research and Applications, NOAA/NESDIS, Washington, D.C. \\ Timothy W. OWEN \\ National Climatic Data Center, Asheville, North Carolina
}

(Manuscript received 17 April 1998, in final form 8 August 1998)

\begin{abstract}
Monthly and seasonal relationships between urban-rural differences in minimum, maximum, and average temperatures measured at surface-based observation stations were compared to satellite-derived Advanced Very High Resolution Radiometer estimates of a normalized difference vegetation index (NDVI) and surface radiant temperature $\left(T_{\text {sfc }}\right)$. The relationships between surface- and satellite-derived variables were developed during 1989-91 and tested on data acquired during 1992-93. The urban-rural differences in air temperature were linearly related to urban-rural differences in the NDVI and $T_{\text {sfe. }}$. A statistically significant but relatively small (less than 40\%) amount of the variation in these urban-rural differences in air temperature [the urban heat island (UHI) bias] was associated with variation in the urban-rural differences in NDVI and $T_{\text {sfc }}$. A comparison of the satellite-based estimates of the UHI bias with population-based estimates of the UHI bias indicated similar levels of error. The use of satellite-derived data may contribute to a globally consistent method for analysis of the urban heat island bias.
\end{abstract}

\section{Introduction}

The influence of urbanization and land use/land cover (LULC) on several meteorological variables has been well documented (e.g., Landsberg 1981; Kukla et al. 1986; Karl et al 1988; Changnon 1992; Gallo et al. 1993, 1996, 1999). Gallo et al. (1996) observed that weather observation stations with a predominantly urban-related LULC usually displayed a lower diurnal temperature range $(\mathrm{DTR}=$ maximum - minimum temperature $)$ compared to those stations with predominantly rural LULC. Gallo et al. (1996) speculated that the transition of the LULC from predominantly rural to a more urban setting can have an impact on the trends in temperature (specifically a decrease in the diurnal temperature range) similar to that which would be expected under an enhanced greenhouse warming scenario. Thus, the LULC influences on temperatures, as opposed to greenhouse warming influences, need to be clearly defined. Ultimately, adjustments based on LULC changes must be made to the minimum and maximum temperature records to account for the influence of urbanization on the observed temperatures and derived DTR.

The population of cities associated with weather ob-

Corresponding author address: Kevin P. Gallo, National Climatic Data Center, 151 Patton Ave., Asheville, NC 28801.

E-mail: Kevin.P.Gallo@noaa.gov servation stations is currently used to adjust the temperatures observed for the U.S. Historical Climatology Network (HCN). The U.S. HCN (Easterling et al. 1996) dataset is updated periodically and includes minimum and maximum monthly temperature data that have been adjusted to remove biases caused by changes in the time of observation, changes in instruments, movement of weather stations, and urbanization. The populationbased urban adjustments to the dataset are based on the analysis of Karl et al. (1988). In development of these adjustments, Karl et al. (1988) detected the influence of urbanization on long-term temperature records [the urban heat island (UHI) bias] for cities with populations less than 10000 .

No routine adjustments are currently made to global climatological datasets. The relationship between urban and rural temperature bias and population has been found by Oke (1973) to differ between North American and European cities. Other limitations to the use of population statistics as an estimator of the UHI bias include the lack of a globally consistent population data. Additionally, population data associated with a geographically defined area can be difficult to relate to the population (or LULC) in the immediate vicinity of a weather station. Thus, population alone does not appear to be a globally applicable method for evaluating and removing the UHI bias.

Gallo et al. (1993) observed that the satellite-derived 
TABLE 1 . The 28 cities included in the analyses, abbreviations used in Fig. 4, and number of urban and rural stations analyzed for each city.

\begin{tabular}{|c|c|c|c|}
\hline City & Acronym & $\begin{array}{l}\text { No. of } \\
\text { urban }\end{array}$ & No. of rural \\
\hline Allentown, PA & ALTN & 7 & 8 \\
\hline Bangor, ME & BNGR & 1 & 3 \\
\hline Billings, MT & BLGS & 2 & 3 \\
\hline Bismarck, ND & BSMK & 1 & 5 \\
\hline Cincinnati, $\mathrm{OH}$ & CNTI & 5 & 5 \\
\hline Colorado Springs, CO & COSP & 2 & 4 \\
\hline Columbia, MO & CL-M & 3 & 5 \\
\hline Columbia, SC & CL-S & 2 & 7 \\
\hline Dallas, TX & DLAS & 3 & 4 \\
\hline Duluth, MN & DLTH & 4 & 5 \\
\hline Eugene, OR & EGNE & 1 & 9 \\
\hline Fargo, ND & FRGO & 2 & 4 \\
\hline Great Falls, MT & GRFL & 1 & 4 \\
\hline Little Rock, AR & LTRK & 4 & 4 \\
\hline Lubbock, TX & LBCK & 1 & 3 \\
\hline Milwaukee, WI & MLKE & 4 & 1 \\
\hline Montgomery, AL & MTGY & 2 & 5 \\
\hline Nashville, TN & NSVL & 2 & 7 \\
\hline New Orleans, LA & NOLS & 3 & 4 \\
\hline Omaha, NE & OMHA & 2 & 8 \\
\hline Orlando, FL & OLDO & 4 & 2 \\
\hline Richmond, VA & RMND & 2 & 5 \\
\hline San Antonio, TX & SATO & 2 & 5 \\
\hline Seattle, WA & STLE & 7 & 8 \\
\hline Spokane, WA & SPKN & 2 & 4 \\
\hline Waterloo, IA & WTLO & 1 & 5 \\
\hline Wichita, KS & WTCA & 2 & 2 \\
\hline Worcester, MA & WSTR & 10 & 6 \\
\hline
\end{tabular}

normalized difference vegetation index (NDVI) sampled over urban and rural regions composed of a variety of land surface environments were linearly related to the differences in observed urban and rural temperatures. The difference in the NDVI between urban and rural environments appears to be an indicator of the differences in the surface properties (i.e., evaporation and heat storage capacity) between the two environments. The objectives of this study were to extend the analysis of Gallo et al. (1993) to a multiseasonal and multiyear analysis of the relationships between in situ observations of maximum, minimum, and average temperature and satellite-derived land surface radiant temperature $\left(T_{\mathrm{sfc}}\right)$ and NDVI. The overall objective was to supplement the current, population-based, UHI adjustments to maximum, minimum, and average temperature recorded at weather observation stations in the United States and potentially provide a methodology applicable to global climatological data networks.

\section{Methodology}

Twenty-eight cities (Table 1) and their associated urban and rural weather observation stations were selected from the 37 identified in the analysis of Gallo et al. (1993). The selected cities met the criterion that the difference between the lowest and highest station elevation was less than $500 \mathrm{~m}$. The populations associated

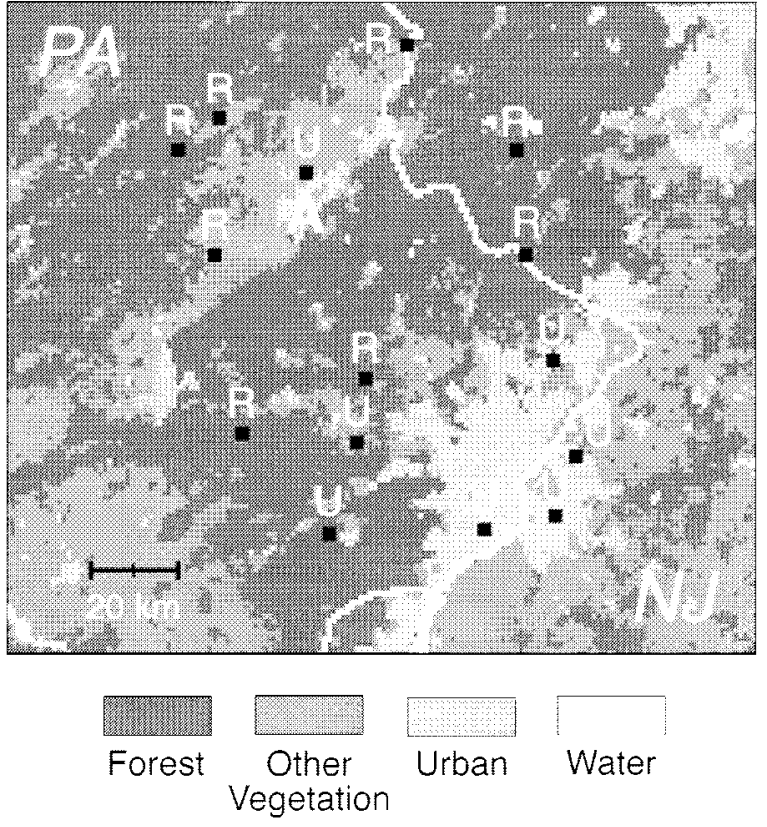

FIG. 1. Urban (U) and rural (R) stations in Pennsylvania (PA) and New Jersey (NJ) associated with the analysis of Allentown, PA (A). General land cover classes were derived from the International Geosphere-Biosphere global 1-km land cover data product for North America (Loveland and Belward 1997).

with the cities ranged from less than 80000 (Great Falls, Montana) to greater than 3000000 (Dallas, Texas). The daily minimum and maximum temperatures from 1989 to 1993 were obtained for selected urban and rural weather stations of the U.S. Cooperative Station Network that were located approximately within a $1^{\circ} \times 1^{\circ}$ square centered on the latitude and longitude of the selected cities.

The individual stations were manually classified as urban (population $\geq 10000$ ) or rural (population $<10000$ ) based on population and ancillary factors. Stations located in cities with populations less than 10000 , yet adjacent to urban areas, were considered urban. Generally, there were more rural stations than urban for the analyzed cities (Table 1); exceptions included Cincinnati and Little Rock (same number of stations) and Milwaukee, Orlando, and Worcester (greater number of urban stations). The stations utilized for the analysis of Allentown, Pennsylvania, are displayed in Fig. 1. The stations included several from the Philadelphia metropolitan region. The general land cover classes of the Allentown region, derived from the global 1-km land cover dataset (Loveland and Belward 1997), are also displayed in Fig. 1.

Satellite-derived data used in this study included biweekly composite products produced at the USGS EROS Data Center (Eidenshink 1992). The composite products are based on daily full-resolution $(1.1 \mathrm{~km}$ at nadir) Advanced Very High Resolution Radiometer (AVHRR) scenes that were geometrically registered to 
a Lambert azimuthal equal-area map projection. Each map cell of the georegistered products represents $1 \mathrm{~km}^{2}$. The daily scenes were composited on a biweekly basis such that the data value from the scene that exhibited the largest value of the normalized difference vegetation index,

$$
\mathrm{NDVI}=\frac{\text { near-IR }- \text { visible }}{\text { near-IR }+ \text { visible }},
$$

was retained for each grid cell in the composite product. The visible $(0.58-0.68 \mu \mathrm{m})$, near infrared (IR) $(0.72$ $1.1 \mu \mathrm{m})$, and thermal IR associated with the maximum NDVI value were also retained in the composite product.

Calibrated thermal IR data of channels 4 (T4; $10.3-$ $11.3 \mu \mathrm{m})$ and $5(\mathrm{~T} 5 ; 11.5-12.5 \mu \mathrm{m})$ on the National Oceanic and Atmospheric Administration (NOAA) AVHRR were used to estimate apparent surface temperature $\left(T_{\text {sfc }},{ }^{\circ} \mathrm{C}\right)$ as

$$
T_{\text {sfc }}=\mathrm{T} 4+3.3(\mathrm{~T} 4-\mathrm{T} 5),
$$

for a surface emissivity of 1.0, as described by Price (1990). The emissivity values associated with the urban and rural AVHRR samples of T4 and T5 data were not available. Oke (1987) cited emissivity values for vegetation (agricultural crops, deciduous and coniferous forests) that ranged from 0.90 to 0.97 , while values for urban materials (concrete, asphalt, and stone) ranged from 0.71 to 0.95 . Roth et al. (1989) estimated that the suppressed differences in $T_{\text {sfc }}$, due to unaccounted differences in emissivity, could be as much as $1.5^{\circ} \mathrm{C}$. The visible, near-IR, and thermal IR data were not adjusted for atmospheric properties because relative, rather than absolute, differences in the vegetation index and $T_{\text {sfc }}$ were computed. Roth et al. (1989) suggested, based on Carlson (1986), that the error in relative temperature differences due to horizontal differences in atmospheric properties between urban and rural regions was approximately $1^{\circ} \mathrm{C}$ or greater.

The use of thermal IR data to assess the urban-rural differences in air temperature is admittedly complex. Roth et al. (1989) recognized that a satellite views only one of the many surfaces associated with the structures within the urban environment. Voogt and Oke (1997) discuss the complex influence of sensor view angle effects on observations of thermal IR data in urban environments.

Additionally, Gallo and Tarpley (1996) observed that the urban-rural differences in $T_{\text {sfc }}$ data available from composite products were not as consistent as the differences in NDVI values. However, as winter months (November-February) were included in this study, and the lack of green vegetation made NDVI useless in many regions of the United States during these months, the composite-based $T_{\text {sfc }}$ data [Eq. (2)] were included in this study.

While more elaborate techniques for "adjustments" of visible, near-, and thermal IR data exist, the data used in this study were minimally processed. Potential future applications of the methodology developed in this study include a global analysis of the urban heat island bias. A global 1-km AVHRR dataset, very similar to the dataset used in this study, is under preparation with guidelines developed by the International Geosphere-Biosphere Programme (Townshend et al. 1994). While local surface and atmospheric adjustments could have been made within this study, similar adjustments would not be possible on a global scale. Thus, these potential adjustments were not used in conjunction with the satellite-derived data included in this study in an effort to determine if the minimally processed data were useful for assessment of the urban heat island bias.

The visible and near-IR data were used to screen composite data for cloud contamination based on recommendations of Stowe (1991). Data were assumed to be cloud contaminated when the visible reflectance values were greater than $44 \%$ or when the near-IR/visible ratio was between 0.9 and 1.1. Data defined as cloud contaminated were not utilized in the analyses. The visible, near-IR, and thermal IR data were sampled for $3 \times 3$ pixel $(\mathrm{km})$ windows centered on each weather station of each urban area included in the study. Data acquired over water bodies, as defined by USGS digital data (USGS 1991), were excluded from analyses.

The analysis of each city included the average of the satellite and in situ data for the rural and urban stations associated with each of the cities (Table 1). Urban and rural differences in biweekly, monthly, and seasonal values of $T_{\text {sfc }}$ and the NDVI were computed for each city (Table 1) and compared to urban and rural differences in minimum, maximum, and average temperature $\left(T_{\min }\right.$, $T_{\max }$, and $T_{\text {avg }}$, respectively) over the same time intervals. The in situ air temperature values were aggregated from daily values for the respective stations acquired from the NOAA National Climatic Data Center. The $T_{\mathrm{sfc}}$ and NDVI biweekly composites did not directly match the beginning and end of the calendar-based months or seasons. As a result, the biweekly composites were combined such that those that included data primarily from a specific month were included in the composite for that month. The daily air temperature data were averaged over the "monthly" or "seasonal" intervals specified by the start and end dates of the $T_{\text {sfc }}$ and NDVI composite intervals. The data of 1989-91 were used in model development, and the models were evaluated with the data of 1992 and 1993.

\section{Results and discussion}

\section{a. Seasonal trends in urban-rural differences in air temperature and NDVI}

The general urban-rural trends in air temperature and NDVI for the 28 cities are displayed in Fig. 2. The composite satellite data were not available on a continuous basis as only one biweekly product per month was 


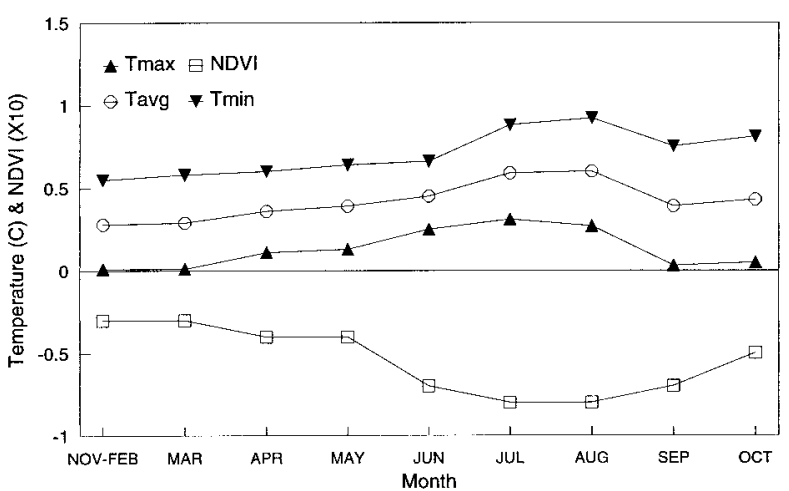

FIG. 2. Averaged monthly trends (1989-91) of urban-rural differences in minimum, maximum, and average temperatures and the NDVI for the 28 cities included in the analysis.

available for the November-February interval. The air temperature and NDVI values during this interval were averaged (and displayed as months Nov-Feb, Fig. 2). In general, the urban stations displayed greater $T_{\min }$, $T_{\max }$, and $T_{\text {avg }}$ values than the rural stations through all seasons (all urban-rural difference values $>0$ in Fig. 2 ). The rural stations displayed the greater NDVI values through all seasons (all urban-rural difference values of NDVI $<0$ in Fig. 2). Generally, as the urban-rural difference in NDVI increases, to a maximum in July and August, the greatest urban-rural differences in $T_{\max }$, $T_{\min }$, and $T_{\text {avg }}$ are observed. The greatest urban-rural differences in air temperature are observed for the minimum temperature, as had been observed by Karl et al. (1988). Urban-rural differences in the NDVI and air temperatures were evident throughout the year except for $T_{\max }$ during the November-March interval.

Many of the cities examined displayed trends similar to those of Fig. 2, such as those displayed for Great Falls, Montana (Fig. 3). The seasonal urban-rural temperature differences for Great Falls were among the greatest observed. Some of these differences may be attributable to the elevation differences between the stations included in the analysis of Great Falls. The Great Falls airport (urban location) is located at $1117 \mathrm{~m}$, while the four rural locations were at elevations that ranged from 1286 to 1595 m. Thus, Great Falls was nearly excluded from the analysis due to the elevation difference between the stations $(478 \mathrm{~m})$. Rather than exclusion of cities with station elevation differences of greater than an admittedly arbitrary value of $500 \mathrm{~m}$, future analyses should attempt to include the impact of elevation differences in the prediction of the urban-rural temperature differences.

Another city that displayed trends similar to the mean values (Fig. 2) was Allentown, Pennsylvania (Fig. 4). While the analysis was centered on Allentown, most of the urban samples for this analysis were associated with the Philadelphia, Pennsylvania, region (Fig. 1). The greatest difference in elevation between stations included in the Allentown analysis was $222 \mathrm{~m}$. The urban

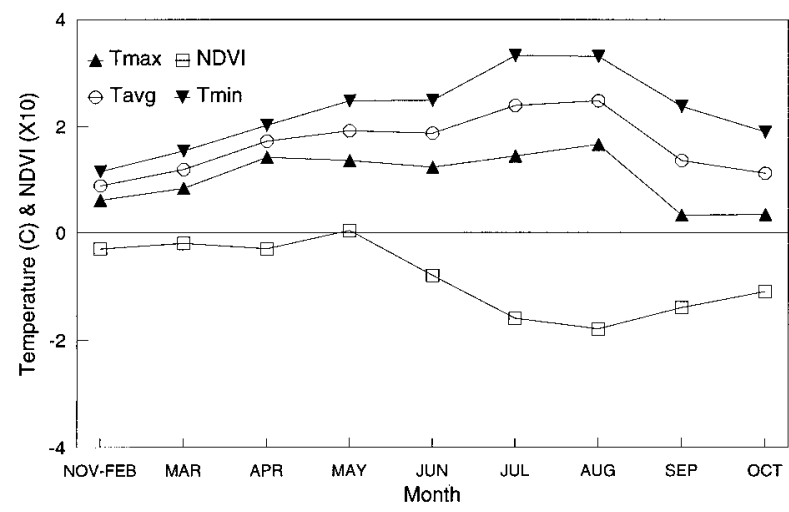

FIG. 3. Averaged monthly trends (1989-91) of urban-rural differences in minimum, maximum, and average temperatures and the NDVI for Great Falls, MT.

and rural differences in the maximum, minimum, and average temperatures were similar for the NovemberApril interval. Similar to the mean values (Fig. 2) the greatest urban-rural differences in minimum temperature occurred with the greatest urban-rural differences in NDVI.

There were also some interesting departures from the general trends as displayed in Fig. 2. Wichita, Kansas, displayed (Fig. 5) a stark contrast to the general trends, as the rural stations showed the greatest NDVI values during the spring, while during the summer and fall months the urban stations displayed the greatest NDVI. In conjunction with the rural stations display of lower NDVI than the urban during the summer and fall months, the rural air temperatures were warmer than the urban temperatures during this interval. These trends are a direct result of the seasonal changes in LULC in the Wichita region. The rural parts of this region are dominated by agriculture, primarily winter wheat. The winter wheat is planted in fall (September-October) and is at maximum display of green leaf area during the spring months. During late spring the leaves lose their green coloration and harvest occurs during summer

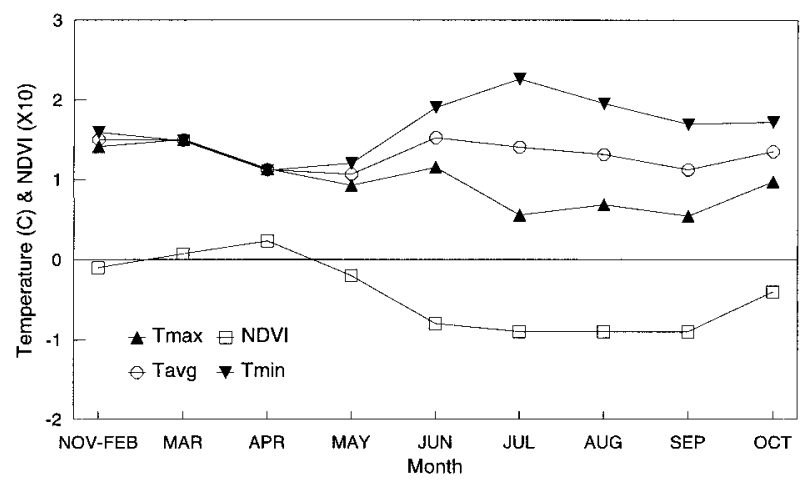

FIG. 4. Averaged monthly trends (1989-91) of urban-rural differences in minimum, maximum, and average temperatures and the NDVI for Allentown, PA. 


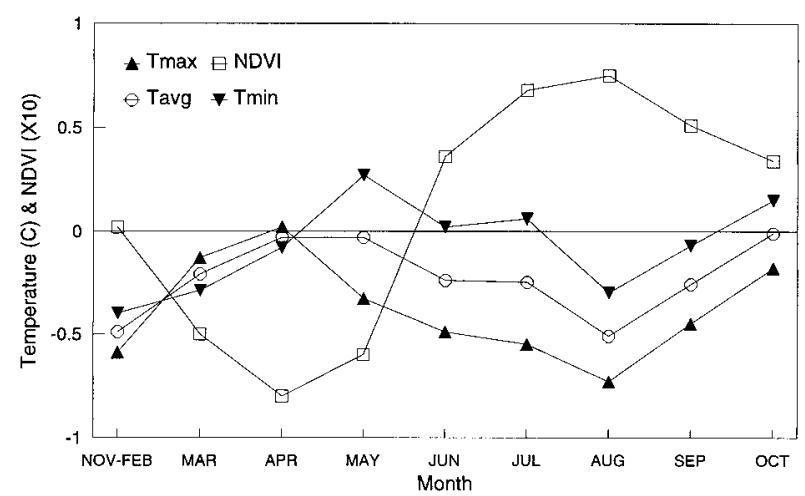

FIG. 5. Averaged monthly trends (1989-91) of urban-rural differences in minimum, maximum, and average temperatures and the NDVI for Wichita, KS.

(June-July). Thus, during the summer months the NDVI values associated with those stations in the rural area around Wichita are at their minimum, as the LULC is either a nongreen wheat crop or bare soil. The urban stations of Wichita (Fig. 5), in contrast to the general trends (Fig. 2), exhibited greater NDVI (urban-rural NDVI difference is positive) and lower temperatures (urban-rural difference is a negative number) than the rural stations during the summer and fall months.

The variations in, and interdependency of, land cover and air temperature over local and regional scales as observed in this study has been suggested by others (e.g., Pielke and Avissar 1990; Stohlegren et al. 1998). Stohlegren et al. (1998) examined model results, in situ observations, and ancillary data to study how changes in land use practices in the Great Plains of the United States may influence the regional climate in adjacent areas of the Rocky Mountains. The authors suggest that the current alteration of natural vegetation in this region, with increased amounts of irrigated vegetation in urban and rural areas, has resulted in regionally cooler temperatures that could mask any warming trends associated with increases in $\mathrm{CO}_{2}$ and other greenhouse gases. The Wichita example (Fig. 5), where in summer months the irrigated "urban" locations exhibited cooler air temperatures than the surrounding rural environments, would seem to follow the Stohlegren et al. (1998) scenario. Thus, urbanization (that includes irrigated vegetation) of some arid or semiarid regions might mask any greenhouse warming signal. This phenomena requires further examination since others (Cayan and Douglas 1984) have found that temperature trends have increased due to increased urbanization in several cities located in the arid southwestern United States.

\section{b. Monthly and seasonal relationships among air temperatures, $N D V I$, and $T_{s f c}$}

Similar to the methodology of Gallo et al. (1993) the urban-rural differences in $T_{\min }, T_{\max }$, and $T_{\text {avg }}$ were modeled as a linear functions of the urban-rural differences

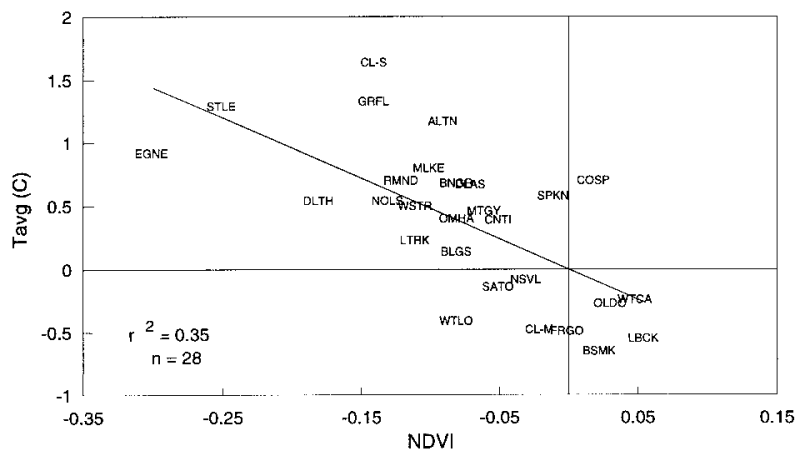

FIG. 6. Relationship between urban-rural differences in average temperature and the NDVI for the month of September (data averaged over 1989-91). City names associated with abbreviations within figure are listed in Table 1.

in NDVI (Fig. 6) and $T_{\text {sfc }}$. Generally, greater urbanrural differences in NDVI were associated with greater differences in urban-rural $T_{\text {avg }}$ (e.g., Fig. 6), $T_{\min }$, and $T_{\max }$. The model results that included the coefficient of determination $\left(r^{2}\right)$ and root-mean-square error (rmse) values were compared for each month. The term $T_{\text {sfc }}$ was determined to be a better predictor of the in situ temperature variables during March-June, while NDVI was the better predictor during July-October. The NDVI was generally associated with a greater amount of the variation in the in situ temperature variables than was $T_{\text {sfc }}$. The NDVI was associated with $16 \%$ (October) to $35 \%$ (September) of the variation in $T_{\text {avg }}$, while $T_{\text {sfc }}$ was associated with only $8 \%$ (April) to $24 \%$ (May) of the variation in $T_{\text {avg }}$ (Table 2a). The NDVI displayed relatively low $r^{2}$ values when used as a predictor of $T_{\max }$ (Table $2 \mathrm{~b}$ ), while $T_{\text {sfc }}$ displayed similarly low values when used as a predictor for $T_{\max }$ (Table 2b) and $T_{\min }$ (Table 2c).

The seasonal analyses (Tables $3 \mathrm{a}-\mathrm{c}$ ) included the use and evaluation of biweekly, monthly, and seasonal composites when data were available. During the spring months (March-May) all biweekly composites during this interval (1989-91) were used for the derivation of the urban and rural values of NDVI and $T_{\text {sfc }}$. Similarly, the monthly composites during this interval were analyzed, as were composites produced over the entire interval. Since only one biweekly composite per month

TABLE 2a. Results from 1989-91 urban heat island analysis of monthly urban-rural differences in $T_{\text {arg }}$ for 28 metropolitan areas. Relationships were significant at $\alpha=0.01$ unless noted otherwise.

\begin{tabular}{llcccc}
\hline \hline Month & Predictor & $b_{0}$ & $b_{1}$ & $r^{2}$ & rmse \\
\hline Mar & $T_{\text {sfc }}$ & 0.18 & 0.11 & 0.18 & 0.77 \\
Apr & $T_{\text {scc }}$ & 0.28 & 0.02 & 0.08 & 0.74 \\
May & $T_{\text {scc }}$ & 0.24 & 0.11 & 0.24 & 0.73 \\
Jun & $T_{\text {sc }}$ & 0.34 & 0.06 & 0.17 & 0.83 \\
Jul & NDVI & 0.22 & -4.6 & 0.28 & 0.60 \\
Aug & NDVI & 0.18 & -4.9 & 0.32 & 0.57 \\
Sep & NDVI & 0.01 & -4.8 & 0.35 & 0.57 \\
Oct & NDVI & 0.21 & -3.5 & 0.16 & 0.64 \\
\hline
\end{tabular}


TABLE 2b. Results from 1989-91 urban heat island analysis of monthly urban-rural differences in $T_{\max }$ for 28 metropolitan areas. Relationships were significant at $\alpha=0.01$ unless noted otherwise.

\begin{tabular}{llclll}
\hline \hline Month & Predictor & $b_{0}$ & $b_{1}$ & \multicolumn{1}{c}{$r^{2}$} & rmse \\
\hline Mar & $T_{\text {sfc }}$ & -0.12 & 0.14 & 0.17 & 0.98 \\
Apr & $T_{\text {sfc }}$ & 0.0 & 0.02 & $0.04 *$ & 0.99 \\
May & $T_{\text {sfc }}$ & -0.05 & 0.14 & 0.20 & 1.0 \\
Jun & $T_{\text {sfc }}$ & 0.13 & 0.06 & 0.13 & 1.1 \\
Jul & NDVI & 0.10 & -2.6 & $0.06^{* *}$ & 0.81 \\
Aug & NDVI & -0.02 & -3.5 & 0.10 & 0.85 \\
Sep & NDVI & -0.33 & -4.6 & 0.18 & 0.83 \\
Oct & NDVI & -0.12 & -2.8 & $0.07 * *$ & 0.82 \\
\hline
\end{tabular}

* Significance at $\alpha=0.1$.

** Significance at $\alpha=0.05$.

was available during the winter (defined as DecemberFebruary) months, only biweekly and seasonal composite intervals were analyzed.

Generally the seasonal satellite-based predictors display (Table 3) similar trends to the monthly data (Table 2) such that NDVI was a better predictor of urban-rural air temperature differences during the summer and fall, while $T_{\text {sfc }}$ was more useful during the spring and winter. The composite intervals that provided the best relationship between the satellite predictors and the air temperatures varied with season. A seasonal composite was found most useful during spring (March-May), most likely because of the greater probability of cloud contamination during this interval. The seasonal, compared to monthly, composite provided a greater opportunity for cloud-free observations. Monthly composites were most appropriate during the summer (June-August) and fall (September-November). The biweekly composites were found to be slightly more useful than seasonal composites for the winter.

\section{c. Comparison of satellite- and population-based estimates urban heat island bias}

The monthly and seasonal estimates of UHI adjustments derived from the satellite-based methodology and the population-based methodology were compared as follows. Five of the 28 cities included in the initial analysis were withheld (Allentown, Pennsylvania; Spokane, Washington; Great Falls, Montana; New Orleans,

TABLE 2c. Results from 1989-91 urban heat island analysis of monthly urban-rural differences in $T_{\min }$ for 28 metropolitan areas. Relationships were significant at $\alpha=0.01$ unless noted otherwise.

\begin{tabular}{llcccc}
\hline \hline Month & Predictor & $b_{0}$ & $b_{1}$ & $r^{2}$ & rmse \\
\hline Mar & $T_{\text {sfc }}$ & 0.49 & 0.09 & 0.10 & 0.85 \\
Apr & $T_{\text {sfc }}$ & 0.55 & 0.03 & 0.10 & 0.77 \\
May & $T_{\text {sfc }}$ & 0.53 & 0.08 & 0.15 & 0.53 \\
Jun & $T_{\text {sfc }}$ & 0.56 & 0.05 & 0.16 & 0.76 \\
Jul & NDVI & 0.34 & -6.7 & 0.28 & 0.84 \\
Aug & NDVI & 0.38 & -6.4 & 0.30 & 0.77 \\
Sep & NDVI & 0.35 & -5.1 & 0.20 & 0.87 \\
Oct & NDVI & 0.56 & -4.1 & 0.12 & 0.89 \\
\hline
\end{tabular}

TABLE 3a. Results from 1989-91 urban heat island analysis of seasonal urban-rural differences in $T_{\text {avg }}$ for 28 metropolitan areas. All satellite-based predictors of urban-rural temperature differences were significant at $\alpha=0.01$.

\begin{tabular}{lccccc}
\hline \hline Season & $\begin{array}{c}\text { Satellite } \\
\text { predictor }\end{array}$ & $b_{0}$ & $b_{1}$ & $r^{2}$ & rmse \\
\hline Spring & $T_{\text {sfc }}$ & 0.28 & 0.10 & 0.26 & 0.69 \\
Summer & NDVI & 0.21 & -4.4 & 0.18 & 0.70 \\
Fall & NDVI & 0.12 & -4.1 & 0.24 & 0.61 \\
Winter & $T_{\text {sfc }}$ & 0.20 & 0.09 & 0.10 & 0.84 \\
\hline
\end{tabular}

TABLE 3b. Results from 1989-91 urban heat island analysis of seasonal urban-rural differences in $T_{\max }$ for 28 metropolitan areas. All satellite-based predictors of urban-rural temperature differences were significant at $\alpha=0.01$.

\begin{tabular}{lccccc}
\hline \hline Season & $\begin{array}{c}\text { Satellite } \\
\text { predictor }\end{array}$ & \multicolumn{1}{c}{$b_{0}$} & $b_{1}$ & $r^{2}$ & rmse \\
\hline Spring & $T_{\text {sfc }}$ & -0.02 & 0.12 & 0.19 & 1.00 \\
Summer & NDVI & 0.06 & -2.8 & 0.05 & 0.94 \\
Fall & NDVI & -0.22 & -3.7 & 0.12 & 0.83 \\
Winter & $T_{\text {sfc }}$ & -0.09 & 0.08 & 0.06 & 0.99 \\
\hline
\end{tabular}

TABLE 3c. Results from 1989-91 urban heat island analysis of seasonal urban-rural differences in $T_{\min }$ for 28 metropolitan areas. All satellite-based predictors of urban-rural temperature differences were significant at $\alpha=0.01$.

\begin{tabular}{llcccc}
\hline \hline Season & $\begin{array}{c}\text { Satellite } \\
\text { predictor }\end{array}$ & $b_{0}$ & $b_{1}$ & $r^{2}$ & rmse \\
\hline Spring & $T_{\text {sfc }}$ & 0.58 & 0.08 & 0.19 & 0.66 \\
Summer & NDVI & 0.36 & -5.9 & 0.23 & 0.81 \\
Fall & NDVI & 0.46 & -4.5 & 0.16 & 0.88 \\
Winter & $T_{\text {sfc }}$ & 0.50 & 0.10 & 0.10 & 0.99 \\
\hline
\end{tabular}

Louisiana; and San Antonio, Texas) and revised regression relationships between urban-rural differences in the air temperatures, NDVI, and $T_{\text {sfc }}$ were derived from the data of 1989-91. The revised equations were evaluated with 1992 and 1993 air temperatures, NDVI, and $T_{\text {sfc }}$ data for the five stations withheld from the equation development. Additionally, the 1992 and 1993 populations associated with the five stations were estimated and used with the Karl et al. (1988) methodology to estimate the UHI adjustments.

Although the population-based adjustments to the U.S. HCN dataset are made on a monthly basis, seasonally based equations (Karl et al. 1988) are utilized and applied on a monthly basis. The equation developed for summer, which includes June, July, and August, is applied to the air temperature data observed for each individual month. Since the population adjustments are made on an annual basis, the same UHI adjustments are essentially applied to the maximum, minimum, and average temperatures for each month during a given season.

The satellite-based estimates of the heat island bias included identification of a single urban station for each of the five cities. The urban sample of NDVI and $T_{\text {sfc }}$ were extracted for a $3 \mathrm{~km} \times 3 \mathrm{~km}$ window centered on 
TABLE 4. Results of error analysis for five cities presented as differences in predicted (population and satellite methodologies) and observed urban heat island bias of average (avg), maximum ( $\max$ ), and minimum (min) air temperature during 1992 and 1993.

\begin{tabular}{lccccccc}
\hline \hline & \multicolumn{3}{c}{ Population } & & \multicolumn{3}{c}{ Satellite } \\
\cline { 2 - 4 } \cline { 6 - 7 } Month & Avg & Max & Min & Avg & Max & Min \\
\hline Monthly & & & & & & \\
Mar & 0.15 & -0.22 & 0.24 & -0.08 & 0.26 & -0.41 \\
Apr & -0.33 & -0.72 & -0.21 & -0.6 & -0.3 & -0.92 \\
May & -0.13 & -0.43 & -0.1 & -0.14 & 0.34 & -0.61 \\
Jun & -0.24 & -0.69 & -0.08 & -0.6 & -0.12 & -1.07 \\
Jul & -0.23 & -0.75 & 0.01 & -0.45 & -0.17 & -0.77 \\
Aug & -0.25 & -0.5 & -0.28 & -0.48 & 0.1 & -1.03 \\
Sep & -0.1 & -0.3 & 0.02 & -0.47 & -0.01 & -0.99 \\
Oct & 0.04 & -0.01 & 0.01 & -0.35 & 0.16 & -0.93 \\
Mean & -0.14 & -0.45 & -0.04 & -0.40 & 0.03 & -0.84 \\
|Mean| & 0.55 & 0.81 & 0.96 & 0.61 & 0.68 & 0.97 \\
Seasonal & & & & & & \\
Winter & 0.63 & 0.64 & 0.54 & 0.12 & 0.46 & -0.34 \\
Spring & -0.2 & -0.59 & -0.08 & -0.25 & 0.1 & -0.6 \\
Summer & -0.36 & -0.8 & -0.23 & -0.6 & -0.2 & -1.03 \\
Fall & 0.26 & 0.11 & 0.33 & -0.14 & 0.29 & -0.58 \\
Mean & 0.08 & -0.16 & 0.14 & -0.22 & 0.16 & -0.64 \\
|Mean & 0.65 & 0.76 & 0.98 & 0.56 & 0.60 & 0.84 \\
\hline
\end{tabular}

the urban station location. The rural samples of NDVI and $T_{\text {sfc }}$ were extracted for $3 \mathrm{~km} \times 3 \mathrm{~km}$ windows centered on the predefined rural station locations. The mean values, computed from all of the rural samples of a given city, were used for comparison with the urban values. Urban-rural differences in NDVI and $T_{\text {sfc }}$ were computed and used in the regression models to compute the urban-rural differences in maximum, minimum, and average temperatures for each analyzed month and season. The mean (averaged over the five cities) error between the predicted and actual urban-rural differences in air temperature for the satellite- and population-based methodologies is included in Table 4.

Generally, the population- and satellite-based estimates of the UHI bias underpredicted the monthly observed biases. Errors for the population-based estimates ranged from a $0.24^{\circ} \mathrm{C}$ overprediction of the March minimum temperature bias to an underprediction of $0.75^{\circ} \mathrm{C}$ for the July maximum temperature. Errors for the satellite-based methodology ranged from an overprediction of $0.34^{\circ} \mathrm{C}$ for the May maximum temperature to an underprediction of $1.07^{\circ} \mathrm{C}$ for the June minimum temperature. The mean error for the population-based estimates of the UHI bias ranged from $-0.04^{\circ}$ for the minimum temperature to $-0.45^{\circ} \mathrm{C}$ for the maximum temperature, while the error ranged from $-0.84^{\circ}$ to $0.03^{\circ} \mathrm{C}$ for the satellite-based estimates. Absolute values of the mean errors indicated the least error in the estimate of the average temperature bias, with the greatest error in estimates of the minimum temperature bias.

The seasonal analysis displayed less mean error for the average temperature (both methodologies) compared to the monthly analyses. The population- (satellite-) based methods displayed less (more) error for the max- imum and more (less) error for the minimum temperatures compared to the monthly analyses. The absolute mean errors were less for each of the seasonal temperatures estimated with the satellite-based methodology compared to the monthly temperatures. Based on the monthly and seasonal results of the absolute error analysis (Table 4 ) a $0.5^{\circ}$ to $1^{\circ} \mathrm{C}$ error might be anticipated in the UHI bias associated with the satellite- and population-based methodologies.

A portion of the error associated with the satellitebased methodology might be attributed to the rural samples used in the estimation of the UHI bias. In this analysis weather observation stations associated with cities or towns of populations less than 10000 were generally considered rural. Stations with populations less than 10000 yet adjacent to urban areas were considered urban. Karl et al. (1988), however, detected the influence of the UHI bias for cities with populations even less than 10 000. Based on Karl et al.'s results, a city with a population of 10000 would be expected to have minimum $\left(+0.23^{\circ} \mathrm{C}\right)$, maximum $\left(-0.02^{\circ} \mathrm{C}\right)$, and average annual temperatures $\left(+0.11^{\circ} \mathrm{C}\right)$ that differed from truly "rural" locations. Thus, revision of the rural samples used in this analysis might be appropriate.

\section{Summary and conclusions}

Seasonal trends in $T_{\max }, T_{\min }, T_{\text {avg }}$, and NDVI were evaluated for urban and rural stations. In general, the urban stations displayed greater $T_{\min }, T_{\max }$, and $T_{\text {avg }}$ values than the rural stations through all seasons. The rural stations displayed the greater NDVI values through all seasons. As the urban-rural difference in NDVI increases, to a maximum in the summer months of July and August, the greatest urban-rural differences in $T_{\max }$, $T_{\min }$, and $T_{\text {avg }}$ are observed. The greatest urban-rural differences in air temperature are observed for the minimum temperature.

Monthly (March-October) and seasonal (spring, summer, fall, and winter) estimates of the UHI bias were developed from NDVI and $T_{\mathrm{sfc}}$ derived from NOAA AVHRR data. The term $T_{\text {sfc }}$ was determined to be a better predictor of the in situ monthly and seasonal temperature variables during March-June, while NDVI was the better predictor during July-October. The amount of monthly variation in urban-rural difference in $T_{\max }$, $T_{\text {min }}$, and $T_{\text {avg }}$ associated with the variation in NDVI (or $T_{\text {sfc }}$ ), although statistically significant, was only as great as $20 \%, 30 \%$, and $35 \%$, respectively. The errors associated with the satellite-based estimates of UHI bias were similar to those estimated with population data. Monthly analyses would be the minimum time interval recommended for the satellite-based UHI bias methodology included in this study.

Implementation of a satellite-based estimate of the UHI bias will require an additional step not included in this study. While there were urban and rural stations available for the cities analyzed in this study, such avail- 
ability is unlikely for many regions of the world. In these regions, the urban sample of AVHRR data would likely be defined as the sample acquired in the vicinity of the station, potentially the $3 \mathrm{~km} \times 3 \mathrm{~km}$ grid cells centered on the station location. The rural sample would require information on the location of rural landscapes near the observation station location. The use of Defense Meteorological Satellite Program's Operational Linescan System (DMSP/OLS) data (Elvidge et al. 1997a; $1977 b$ ) potentially offers a method for identification of rural landscapes near the observation stations. The DMSP/OLS sensor is very sensitive to low-intensity light emissions, including those associated with cities at night. The OLS data have been used successfully to map urban areas in the United States (Imhoff et al. 1997) and identify urban, suburban, and rural stations associated with the U.S. Historical Climatology Network of stations (Owen et al. 1998). The OLS data will be evaluated in the future for its use to identify rural samples of AVHRR data for estimation of the UHI bias.

Acknowledgments. We are most grateful for the assistance of Suzanne Lenihan with the data processing included in this study. We would also like to thank Dr. Alex Huang of the University of North Carolina at Asheville for his review of this manuscript, and the three anonymous reviewers, as their comments helped to improve this paper. This study was partially supported by the Climate and Global Change Program of NOAA's Office of Global Programs.

\section{REFERENCES}

Carlson, T. N., 1986: Regional-scale estimates of surface moisture availability and thermal inertia using remote thermal measurements. Remote Sens. Rev., 1, 197-247.

Cayan, D. R., and A. V. Douglas, 1984: Urban influences on surface temperatures in the southwestern United States during recent decades. J. Climate Appl. Meteor., 23, 1520-1530.

Changnon, S. A., 1992: Inadvertent weather modification in urban areas: Lessons for global climate change. Bull. Amer. Meteor. Soc., 73, 619-627.

Easterling, D. R., T. R. Karl, E. H. Mason, P. Y. Hughes, and D. P. Bowman, 1996: United States Historical Climatology Network (U.S. HCN) monthly temperature and precipitation data. ORNL/ CDIAC-87, NDP-019/R3, 280 pp. [Available from NTIS, 5285 Port Royal Rd., Springfield, VA 22161.]

Eidenshink, J. E., 1992: The 1990 conterminous U.S. AVHRR data set. Photogramm. Eng. Remote Sens., 58, 809-813.

Elvidge, C. D., K. E. Baugh, E. A. Kihn, H. W. Kroehl, and E. R. Davis, 1997a: Mapping city lights with nighttime data from the DMSP operational linescan system. Photogramm. Eng. Remote Sens., 63, 727-734.

$\longrightarrow,-,-\longrightarrow, \ldots$, and C. W. Davis, 1997b: Relation between satellite observed visible-near infrared emissions, population, economic activity and electric power consumption. Int. J. Remote Sens., 18, 1373-1379.

Gallo, K. P., and J. D. Tarpley, 1996: The comparison of vegetation index and surface temperature composites for urban heat-island analysis. Int. J. Remote Sens., 17, 3071-3076.

— A. L. McNab, T. R. Karl, J. F. Brown, J. J. Hood, and J. D. Tarpley, 1993: The use of NOAA AVHRR data for assessment of the urban heat island effect. J. Appl. Meteor., 32, 899-908.

_ - D. R. Easterling, and T. C. Peterson, 1996: The influence of land use/land cover on climatological values of the diurnal temperature range. J. Climate, 9, 2941-2944.

_ , T. W. Owen, D. R. Easterling, and P. F. Jamason, 1999: Temperature trends of the U.S. Historical Climatology Network based on satellite-designated land use/land cover. J. Climate, 12, $1344-1348$.

Imhoff, M. L., W. T. Lawrence, D. C. Stutzer, and C. D. Elvidge, 1997: A technique for using composite DMSP/OLS "city lights" satellite data to map urban area. Remote Sens. Environ., 61, 361370.

Karl, T. R., H. F. Diaz, and G. Kukla, 1988: Urbanization: Its detection and effect in the United States climate record. J. Climate, 1, 1099-1123.

Kukla, G., J. Gavin, and T. R. Karl, 1986: Urban warming. J. Climate Appl. Meteor., 25, 1265-1270.

Landsberg, H. E., 1981: The Urban Climate. Academic Press, 275 $\mathrm{pp}$

Loveland, T. R., and A. S. Belward, 1997: The IGBP-DIS global 1 $\mathrm{km}$ land cover data set, DISCover: First results. Int. J. Remote Sens., 18, 3289-3295.

Oke, T. R., 1973: City size and the urban heat island. Atmos. Environ., 7, 769-779.

_ 1987: Boundary Layer Climates. Methuen and Co., 435 pp.

Owen, T. W., K. P. Gallo, C. D. Elvidge, and K. E. Baugh, 1998: Using DMSP-OLS light frequency data to categorize urban environments associated with U.S. climate observing stations. Int. J. Remote Sens., 19, 3451-3456.

Pielke, R. A., and R. Avissar, 1990: Influence of landscape structure on local and regional climate. Landscape Ecol., 4, 133-155.

Price, J. C., 1990: Using spatial context in satellite data to infer regional scale evapotranspiration. IEEE Trans. Geosci. Remote Sens., 28, 940-948.

Roth, M., T. R. Oke, and W. J. Emery, 1989: Satellite-derived urban heat islands from three coastal cities and the utilization of such data in urban climatology. Int. J. Remote Sens., 10, 1699-1720.

Stohlgren, T. J., T. N. Chase, R. A. Pielke Sr., T. G. F. Kittel, and J. S. Baron, 1998: Evidence that local land use practices influence regional climate and vegetation patterns in adjacent natural areas. Global Change Biol., 4, 495-504.

Stowe, L. L., 1991: Cloud and aerosol products at NOAA/NESDIS. Palaeogeogr., Palaeoclimatol., Palaeoecol. (Global Planet. Change), 90, 25-32.

Townshend, J. R. G., C. O. Justice, D. Skole, J.-P. Malingreau, J. Cihlar, P. Teillet, F. Sadowski, and S. Ruttenberg, 1994: The 1 $\mathrm{km}$ resolution global data set: Needs of the International Geosphere Biosphere Programme. Int. J. Remote Sens., 15, 34173441 .

USGS, 1991: Hydrologic data sets. Conterminous U.S. AVHRR Companion Disc, USGS, CD-ROM. [Available from USGS, National Mapping Division, EROS Data Center, Sioux Falls, SD 57198.]

Voogt, J. A., and T. R. Oke, 1997: Complete urban surface temperatures. J. Appl. Meteor., 36, 1117-1132. 